\title{
Estranho encontro (1958) e o estilo nascente de Walter Hugo Khouri
}

\section{Estranho encontro (1958) and the new style of Walter Hugo Khouri}

Gabriel Henrique de Paula Carneiro ${ }^{1}$ Artes, da Universidade Estadual de Campinas. Sócio fundador da Abraccine - Associação Brasileira de Críticos de Cinema. Escreveu, entre outros, para a Revista de Cinema e para os sites Revista Zingu! e Cinequanon. Organizou, com Paulo Henrique Silva, os livros Animação brasileira: 100 filmes essenciais (Letramento, 2018) e Curta brasileiro: 100 filmes essenciais (Letramento, 2019). E-mail: ghpcarneiro@gmail.com. 


\section{Resumo}

Com Noite vazia (1964), Walter Hugo Khouri abraçou o cinema moderno e consolidou uma série de características temáticas e formais que se tornaram sinônimos de seu cinema. No entanto, no anterior Estranho encontro (1958), realizado dentro dos princípios de transparência clássica, já há traços que o inflexionam para a modernidade e uma preocupação particular com a composição da atmosfera. O artigo pretende investigar se é possível identificar um estilo nascente já em seu segundo longa-metragem.

Palavras-chave

Walter Hugo Khouri, Estranho encontro, cinema paulista, cinema brasileiro.

\section{Abstract}

With Noite Vazia (1964), Walter Hugo Khouri embraced the modern cinema and consolidated a series of thematic and formal characteristics that have become synonymous with his cinema. Nevertheless, in the previous Estranho encontro (1958), made following the principles of classical transparency, there are already traits that inflect it towards modernity and a particular concern in the composition of the atmosphere. This article seeks to investigate the possibility of identifying a new style in his second feature film.

\section{Keywords}

Walter Hugo Khouri, Estranho encontro, Brazilian cinema. 
Walter Hugo Khouri foi um dos mais prolíficos cineastas brasileiros. Realizou 25 longas-metragens, em mais de 45 anos dedicados à prática cinematográfica, e atravessou os mais diversos modelos de produção - da independente, fora dos estúdios, no começo profissional, ao modelo da Retomada, passando pela Boca do Lixo, pela Embrafilme, por coproduções internacionais, entre outros. O contexto em que seus filmes foram realizados, bem como as possibilidades de produção que encontrou no caminho, certamente influenciaram suas obras, mas é inegável o caráter autoral de seu corpo fílmico.

O filme súmula nesse sentido é Noite vazia (1964), considerado por estudiosos e pelo próprio diretor como um ponto de virada em sua carreira, em que abraça o cinema moderno e condensa os princípios temáticos e estilísticos que guiam toda sua produção seguinte. No longa, dois amigos tentam findar o tédio e a desilusão com duas prostitutas de luxo. A premissa é mote para o cineasta investigar o vazio existencial e o desejo de seus personagens de classe média alta. Para tal, recorre a conceitos filosóficos e psicanalíticos, muitas vezes textualmente explicitados, ao espaço urbano da metrópole como metáfora da impessoalidade e ao erotismo latente, além de uma série de procedimentos formais que marcaram a obra visualmente. Segundo Fernão Ramos (2001, p. 7), "a busca do vazio existencial encontra uma correspondência estilística madura, conformando um todo autoral consistente". Khouri aperfeiçoou alguns recursos, como o uso do zoom (in e out) no rosto dos personagens e de big close-up; uma direção de atores contida; a utilização de poucas locações, com predileção para espaços fechados. São marcas tanto temáticas quanto estilísticas que identificam o cinema de Khouri para o público especializado.

Antes de Noite vazia, Khouri realizou cinco longas, entendidos dentro de outro recorte na carreira do cineasta como uma "fase de juventude"2, o que necessariamente implica uma ideia de superação - e, talvez por isso, sejam menos estudados. 
O melodrama psicológico Estranho encontro (1958) é o segundo filme realizado pelo cineasta e o mais antigo passível de uma análise mais detalhada ${ }^{3}$. O longa opera num modelo eminentemente clássico. No entanto, já é possível identificar nele um estilo nascente. A proposta deste texto é, portanto, entender o lugar de Estranho encontro dentro da carreira de Khouri e investigar de que forma ele se conecta com seus demais filmes, apontando - ou não - traços formais autorais desenvolvidos ao longo de sua obra.

\section{São Paulo, anos 1950: o cinema fora dos estúdios}

A produção cinematográfica paulista se transformou completamente nos anos 1950. Até então, o cenário local restringia-se a uns tantos cinejornais e filmes de curta e média-metragem e a tentativas esparsas e isoladas de longametragem. Na década de 1940, nove longas foram realizados, por exemplo. Com o fim da Segunda Guerra Mundial e o crescimento do país, a burguesia industrial paulista buscou promover a cultura e a arte ao patamar de primeiro mundo. Nesse contexto, são fundados o Museu de Arte de São Paulo (Masp), o Teatro Brasileiro de Comédia (TBC), a Companhia Cinematográfica Vera Cruz, entre outros. A Vera Cruz importou o sistema hollywoodiano de estúdios, em que a companhia controlava o processo inteiro de produção e dominava toda a infraestrutura, mantendo sob contrato profissionais de diversas áreas e um parque técnico enorme, buscando a autossuficiência. Na esteira da Vera Cruz, produtoras como Maristela e Multifilmes foram fundadas.

A efervescência cultural permitiu que, paralelamente, surgisse toda uma classe disposta a realizar filmes. Havia muitos profissionais disponíveis, facilidades de produção, novas legislações protecionistas e um espírito de ocupação de mercado com a possibilidade de transformar o cinema numa profissão efetiva ${ }^{4}$.

O gigante de pedra, seu primeiro longa, não é visto em sua íntegra desde os anos 1960, quando houve um incêndio nos laboratórios da Divulgação Cinematográfica Bandeirantes (AZEREDO, 1969, p. 16). Dado como perdido, foram encontrados e restaurados 15 minutos de O gigante de pedra para a mostra Retrospectiva Walter Hugo Khouri - Meio Século de Cinema, realizada pela Heco Produções, em 2001, no Centro Cultural Banco do Brasil. 
O modelo de estúdios não se limitava à questão da infraestrutura e abrangia uma série de códigos, que pode ser entendida como o cinema clássico hollywoodiano, o qual, segundo Ismail Xavier (2008b, p. 46), é "orientado para uma produção dentro do trinômio naturalismo/ decupagem clássica/ mecanismo de identificação". Tal modelo de produção, conforme aponta David Bordwell (2005, p. 277), "constitui uma configuração particular das opções normalizadas para representar a história e manipular a composição e o estilo".

Mesmo com o modelo de estúdios entrando em colapso no Brasil no final dos anos 1950, serviu como escola para diversos profissionais que seguiram produzindo em outros esquemas em São Paulo. É o caso de Khouri, que começou no cinema em 1951 como assistente de Lima Barreto na preparação de O cangaceiro (1953), para a Vera Cruz. Saiu de lá antes da filmagem para tocar O gigante de pedra. Ainda que não contasse como a mesma infraestrutura, os princípios de transparência do cinema clássico guiam Estranho encontro.

No filme de 1958, Marcos (Mário Sérgio) quase atropela Júlia (Andrea Bayard). É noite, a estrada está deserta e a moça, em pânico. Marcos decide levá-la para seu destino, uma casa de campo. Como o caseiro Rui (Sérgio Hingst) o espera, Júlia precisa se ocultar. Durante o final de semana em que ela permanece escondida no quarto de Marcos, a relação de ambos se estreita e suas histórias pregressas começam a se revelar.

Já no início, o longa busca contextualizar o espectador naquele espaçotempo e brevemente nos apresenta os protagonistas e heróis do filme, com quem buscamos criar uma identificação, reproduzindo uma "'lógica dos fatos' natural", de forma "a dissolver a 'descontinuidade visual elementar' numa continuidade espaço-temporal reconstruída" (XAVIER, 2008b, p. 32, grifo original). O filme segue, assim, preceitos constatados por Bordwell (2005), em que a narração clássica utiliza a técnica cinematográfica como forma de transmitir informações sobre a história através dos personagens, que geralmente buscam atingir determinados objetivos, em uma estrutura dramatúrgica causal. 
Há, no entanto, duas características formais no filme que parecem inflexionálo para a modernidade: o flashback e o raro uso do campo e contracampo em cenas de diálogos.

\section{Elementos disruptores: o flashback e o campo/contracampo}

Pouco depois de chegarem à casa de campo, instalados no quarto, Marcos tenta entender o estado de pânico em que encontrou Júlia. Para responder a esse questionamento, Khouri opta por mostrar um flashback - o único do filme - que justifica o comportamento da personagem. O flashback é uma ferramenta de narração presente já na literatura. Seu uso no cinema remonta aos primórdios e já se encontra nos estudos de 1916 de Hugo Münsterberg (2008, p. 37), sob o nome de "cutback", o "ato mental de lembrar". Ou seja, não há nada de novo ou de moderno na figura do flashback em si. A maneira como Khouri o introduz tampouco. No filme, Júlia, sentada em frente de um espelho e de costas para a câmera, começa a contar sua história. A câmera, num movimento de travelling in, aproxima-se do rosto da personagem refletido no espelho. Ela fala de como começou a trabalhar numa loja de relógios e de como se sente aterrorizada, hoje, por eles. Passamos a ouvir ao fundo um tic-tac de relógio. Ela diz: "foi nessa loja que conheci Hugo". A imagem dela no espelho se funde com uma de um relógio cujo vidro reflete mais opacamente a face de Júlia, a Júlia do passado. Aos poucos a imagem de Júlia em frente ao espelho se desvanece e vemos apenas o relógio com o novo reflexo. Poderia-se aventar que a "fusão temporal, o recuo no tempo indefinido" (BURCH, 2008, p. 28) que Khouri nos mostra, intermediado por dois reflexos, centralizados num relógio (a representação material do tempo), expõe esse recurso, em especial, porque cada rosto - o da Júlia do presente diegético e o da Júlia do passado - aponta a direções opostas, como se houvesse um dissenso entre ambas. No entanto, estão em pleno acordo com o procedimento que Münsterberg (2008, p. 39) já tateia em seu texto, ao falar que "o conjunto novo de cenas [...] ligam-se à cena presente mediante uma lenta transição", que envolve "o aparecimento e o desaparecimento de uma reminscência". 


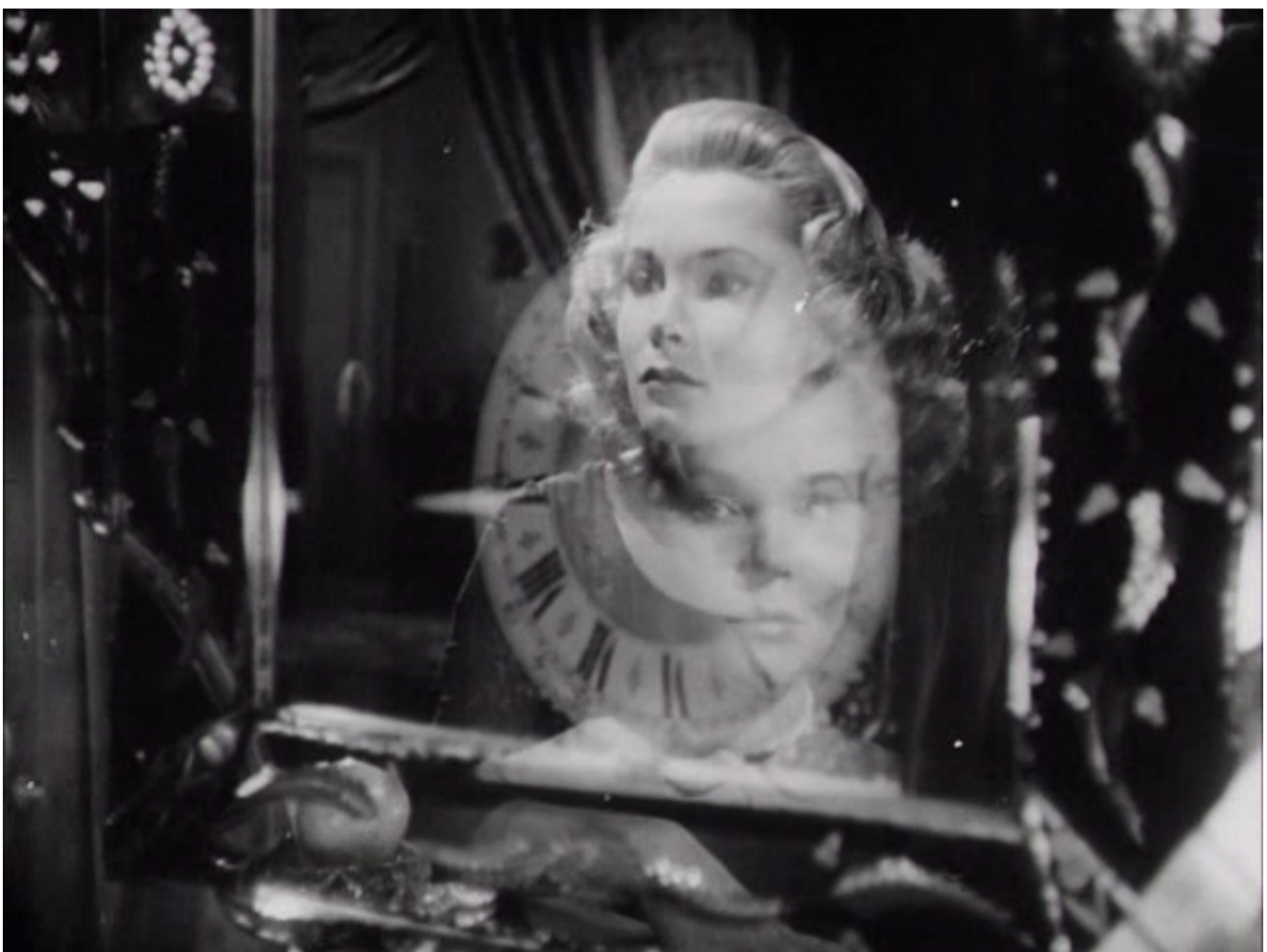

Figura $1^{5}$ : A fusão que inicia o flashback

No flashback, Júlia conta sobre seu passado sofrido, sobre como conheceu Hugo (Luigi Picchi). Ela passou a se encontrar com frequência com ele, que se mostrava muito gentil, e aceitou morar com ele. Vivendo juntos, no entanto, essa experiência se tornou cada vez mais opressiva. Hugo "passou a ser uma figura carrancuda, brutal", que a ignorava, a obrigava a ficar em casa, isolada, rejeitava seus hábitos e agia como se ela estivesse lá para servi-lo. Por isso fugiu.

Em seu estudo sobre flashbacks, Maureen Turim (1989) destaca a relação dessa ferramenta narrativa e a função psicológica tanto no melodrama quanto no filme noir no cinema norte-americano dos anos 1940 e 1950 . Ou seja, ainda dentro dos princípios do cinema clássico, "além de tornar a história subjetiva, outra tendência [...] é associar a estrutura do flashback à psique", implicando, hermeneuticamente, "investigação ou confissão" (TURIM, 1989, p. 143). 
Em Estranho encontro, com o flashback, a trama, até então focada em Marcos, é centralizada em Júlia, tanto em termos narrativos - passamos a acompanhar o filme pelos seus atos, deslocamentos e motivações - quanto estéticos, uma vez que a câmera parece particularmente atraída pela figura de Júlia, seja colocando-a de fato no centro dos enquadramentos, seja privilegiando seu corpo na cena. Inclusive, é a partir do flashback que o filme se firma como melodrama psicológico. Segundo Turim (1989, p. 143), o "melodrama psicológico é essencialmente uma narrativa centrada na personagem feminina cuja psique se torna a base estrutural da narrativa". O que nos guia em Estranho encontro, após o flashback, é a necessidade de fuga de Júlia - e não mais o dilema de Marcos.

A disrupção, no entanto, está em uma escolha visual em particular. Durante os dez minutos de flashback em que Júlia conta sua história com Hugo, em momento algum vemos o rosto dele. Hugo frequentemente aparece de costas para a câmera, na borda do quadro, ou enquadrado de modo que não vejamos seu rosto. Em geral, são planos conjuntos com Júlia, sempre mostrada de modo a evidenciar sua face.
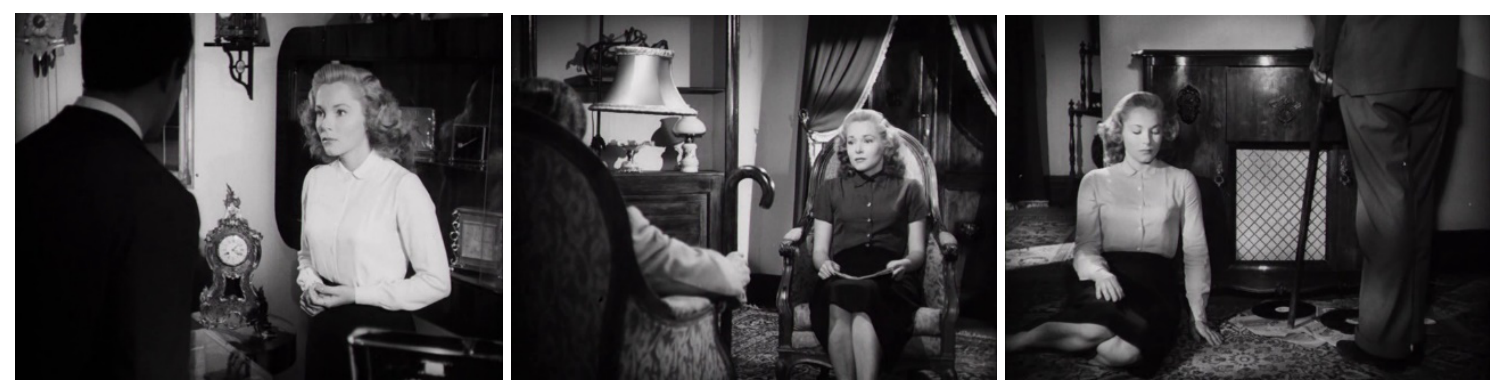

Figuras 2, 3 e 4: O rosto que não se revela

Estranho encontro se ampara na prerrogativa clássica do narrador onisciente invisível, que não expõe a estrutura do meganarrador. Durante o flashback, Júlia clama para si o lugar do narrador, um "narrador segundo", nos termos de André Gaudreault e François Jost (2009, p. 68). Dizem eles que:

Para compreender a história do filme, o espectador deve supor que o narrador [...] assume a responsabilidade pela narrativa audiovisual que vem "recobrir" as imagens, mostrando seu ato narrativo [...]. Ele deve supor, 
em todo caso, que a "audiovisualização" [...] é fiel ao relato verbal [...]. É em nome deste postulado de sinceridade que o espectador está pronto a aceitar numerosas bizarrices ou a apagá-las mentalmente: o fato de que o próprio narrador está no mundo diegético da história que narra, que é mostrada do exterior, também o fato de que cada um dos personagens tem voz própria - e não a do narrador --, e que tudo nos é mostrado em detalhe (fatos, gestos, cenários) enquanto a memória do narrador deveria ser mais limitada, etc. Essas bizarrices [...] são convenções que aceito para poder crer na diegese, para identificar-me com os personagens e com seus pontos de vista. (GAUDREAULT; Jost, 2009, p. 64)

Ou seja, por mais que haja "bizarrices", existe, em estruturas clássicas de flashback, a busca por uma encenação que incorpore as ferramentas análogas ao restante da narrativa. Em Estranho encontro, podemos assumir, dentro do caráter psicológico do melodrama, que o fato de não vermos o rosto de Hugo seria um procedimento mental da protagonista para se proteger, como se quisesse apagar uma situação traumática - uma vez que o flashback seria o ato mental de lembrar sob uma perspectiva subjetiva, isto é, estaríamos de certa forma vendo tal qual Júlia mentaliza a sequência. Não avistar o rosto dele seria despersonalizá-lo, o que poderia facilitar a "promessa de cura" que vê Turim (1989, p. 143) nos flashbacks dos melodramas psicológicos. Dentro dessa concepção, é possível assimilar e entender por que não vemos o rosto de Hugo. No entanto, a racionalização a favor da diegese não elimina o estranhamento causado pela frustração consecutiva que é não ver nunca seu rosto. Khouri, assim, nos nega constantemente um elemento importante do cinema como um todo e central no recorte clássico, que é o rosto, a face do ator ${ }^{7}$. Com isso, faz o espectador questionar a instância narradora e, portanto, o próprio filme.

Efeito semelhante, mas menos brutal, observamos na maneira como Khouri encena diálogos no filme, em especial a partir da cena que inicia o flashback. Em artigo escrito nos anos 1950, A evolução da linguagem cinematográfica, Bazin aponta que, em 1938, ainda no auge da encenação clássica, os filmes eram, fotogenia, que "funciona como pilar econômico do cinema industrial e elemento preponderante de alguns gêneros, como melodrama ou horror", e pode ser resumido como "o efeito quase miraculoso que a visão aproximada do rosto desencadeia nos espectadores, mesclando admiração, inquietação, fascínio e êxtase". 
"quase sem exceção, decupados segundo os mesmos princípios. [...] A técnica característica dessa decupagem era o campo/contracampo" (BAZIN, 2014, p. 105). Xavier (2008b, p. 35) aponta que o campo/contracampo é "o procedimento chave num cinema dramático construído dentro dos princípios da identificação. Seu ponto de aplicação máxima se dá na filmagem de diálogos". No campo/ contracampo, a câmera alterna o ponto de vista entre os interlocutores, em geral diametralmente opostos, de modo que nós vejamos uma combinação das falas e reações desses personagens.

Com este procedimento, o espectador é lançado para dentro do espaço do diálogo. Ele, ao mesmo tempo, intercepta e identifica-se com duas direções de olhares, num efeito que se multiplica pela sua percepção privilegiada das duas séries de reações expressas na fisionomia e nos gestos das personagens. (XAVIER, 2008b, p. 35)

Daniel Dayan chega a indicar o campo/contracampo como principal baliza para o "sistema de sutura", que, para ele, funciona como um "código tutor" do cinema clássico, "construído de modo que mascare a origem e a natureza ideológicas dos enunciados cinematográficos" (2005, p. 321).

Logo na cena em que Marcos e Júlia conversam - e que desencadeia o flashback - já é possível identificar, ainda que tímida, uma tendência que se desenrola no restante do filme. Ao invés de usar o campo/contracampo nos diálogos, Khouri opta por encená-los em planos conjuntos em profundidade de campo. Sua câmera, em geral com mobilidade suave, acompanha os personagens quando se movem, aproxima-se e afasta-se, recompondo o quadro.

Para Bazin (2014, p. 89), que reivindicava o "respeito fotográfico da unidade do espaço", numa perspectiva que objetivava a transparência pela chave do realismo da tomada, o uso da profundidade de campo era uma possibilidade de "supressão parcial da montagem" (2014, p. 106) - pois não é necessário cortar constantemente do campo para o contracampo e vice-versa. Essa "aquisição capital da mise-enscène", se bem utilizada, segundo Bazin (2014, p. 107), é "uma maneira a um só tempo mais econômica, mais simples e mais sutil de valorizar o acontecimento". 
Ao optar por encenar os diálogos em planos conjuntos em profundidade de campo, Khouri possibilita que vejamos a desorientação de Júlia, o que é crucial para a construção dessa personagem na trama. Júlia, em diversos momentos, ao conversar com Marcos sobre situações difíceis a ela, refuga, evitando o contato visual, muitas vezes pondo-se de costas para ele. Numa estrutura de campo/contracampo, em que para manter uma unidade visual de verossimilhança é preciso manter o raccord de olhar, não seria possível esse desprendimento espacial na encenação do diálogo, pois, em profundidade de campo, por vezes, Júlia olha para o mesmo sentido de Marcos. Ou seja, além de permitir que vejamos a reação de ambos simultaneamente, acentua-se o caráter expressivo da atriz Andrea Bayard como Júlia. Tal desorientação da personagem é demonstrada não só por isso, como também pelo olhar vago que, justamente, se escusa de qualquer contato visual direto.
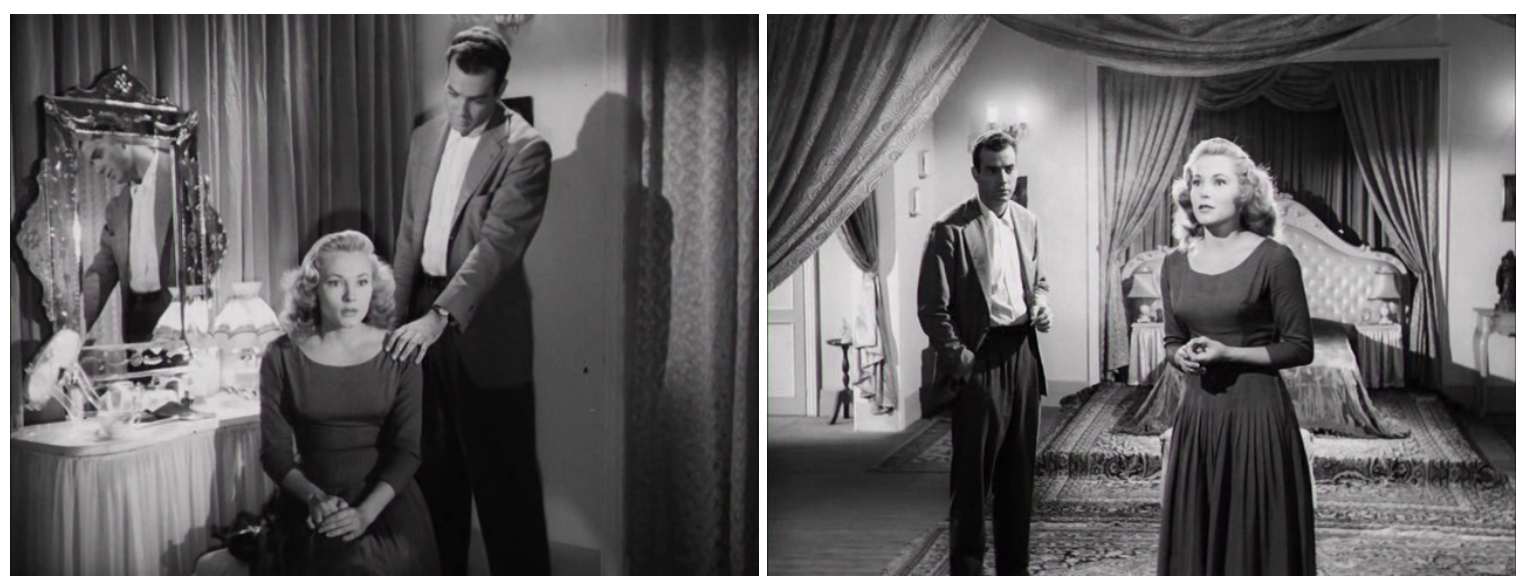

Figuras 5 e 6: Diálogos em profundidade de campo: possibilidade de ausência de contato visual

Em outros momentos, a profundidade de campo permite entender a relação afetiva entre as personagens. Na maioria das vezes, nos diálogos entre Marcos e Júlia, ambos estão fisicamente próximos, centralizados no quadro, o que denota um prazer de estarem juntos. Muito diferente do que vemos entre Marcos e Wanda (Lola Brah), que descobrimos ser sua amante e a dona da casa onde estão. Em determinada cena, ambos conversam à beira do lago. São mostrados em lados opostos do quadro, com o centro vazio. Há uma distância evidente entre 
eles que é acentuada, aí sim, pelo uso do campo/contracampo. Essa é uma das poucas cenas que trazem um campo/contracampo frontal em diálogo no filme. Por ser pouco utilizado, justamente, tal recurso chama a atenção quando recorrido. O uso, nesse caso, marca a separação dos corpos, em planos distintos, o que realça a sensação de ruptura na relação do casal.
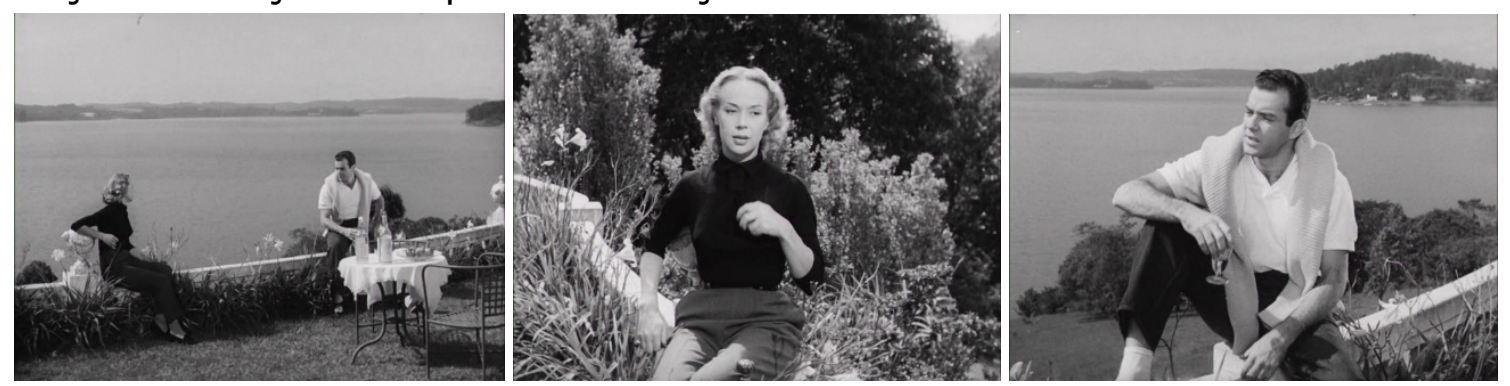

Figuras 7, 8 e 9: O campo e contracampo utilizado para acirrar o distanciamento entre os personagens

\section{A prisão encenada: um estudo de atmosfera}

O cerne de Estranho encontro, pode-se dizer, é a sensação de aprisionamento. Para Júlia, sua relação com Hugo é uma prisão, por isso ela precisa fugir, escapar, porque a falta de liberdade Ihe é nociva. Essa condição é verbalmente explicitada pela personagem durante o flashback.

No entanto, na trama do filme, para Júlia alcançar a liberdade, ela precisa, primeiro, passar por algumas provações, ao menos é o que parece fazer Khouri o que faz bastante sentido dentro da lógica melodramática. Júlia passa, no período em que está na casa de campo, por outras prisões. A começar pelos espaços cênicos a que é restrita: o quarto, o armário, o galpão. À personagem não é permitida a livre circulação.

Para criar um efeito de aprisionamento, Khouri poderia ter filmado a personagem em big close-ups - procedimento comum na carreira posterior do cineasta -, de forma a buscar uma sensação de claustrofobia. No entanto, em Estranho encontro, há uma escolha por planos abertos, em espaços cênicos amplos - que refletem a classe social em que Wanda se insere -, ou seja, tudo parece vasto. Esse paroxismo é central para a construção de algo muito caro a Walter Hugo Khouri: a atmosfera. 
Em entrevista no ano de 1969 sobre sua carreira, o cineasta já apontava a importância da elaboração atmosférica em O gigante de pedra, por exemplo, cujo "valor principal era uma atmosfera muito marcante, cinzenta, triste" (AZEREDO, 1969, p. 16) ${ }^{8}$. Para Inês Gil (2011, p. 95-96), a atmosfera "rege as relações do homem com o seu meio ambiente", ligada a uma "espécie de disposição de espírito e de alma, imanente das 'coisas' do mundo". No senso comum, seria o "tom específico de um espaço". Podemos entender a atmosfera como um efeito de sentido que busca, pela forma, provocar uma emoção no espectador. Segundo Gil (2011, p. 97), "o que caracteriza realmente a atmosfera de um filme é o movimento das imagens (e do seu conteúdo) e o tempo que está ligado a esse movimento"9.

Ao encenar uma prisão em espaços abertos, o cineasta transforma a clausura física numa projeção mental - não importa onde Júlia estiver, ela precisará primeiro se libertar psicologicamente de seu trauma.

A sensação de aprisionamento é reforçada pela forma como Khouri compõe as cenas com Júlia. Segundo Isabel Carmo (2019, p. 119), na obra do diretor, percebe-se "uma forte relação entre várias personagens e o espelho, a fim de ver a si mesmos para além da própria aparência, na busca de uma compreensão, de uma verdade ou de um confronto pessoal em virtude de erros passados". O espelho, portanto, "serve para refletir, não só em seu sentido de espelhamento imagético, mas também de pensar, de especular".

Estranho encontro é repleto de espelhos. A priori, parecem estar lá a favor da composição e da profundidade de campo. Na cena anterior ao flashback, representando inclusive um desmentido das diversas 'influências' que me foram imputadas depois. O simples exame das fotos pode demonstrar uma série de constantes de atmosfera e de composição - de reflexos, água, tristeza, tempos mortos - que apareceriam depois nos outros filmes". Vale dizer que, em 1969, os críticos à obra de Khouri, muitas vezes, consideravam seus filmes como decalques de cineastas como o italiano Michelangelo Antonioni e o sueco Ingmar Bergman, de quem Khouri era admirador confesso - após descobrir Bergman em 1954 com Noites de circo (1953), Khouri escreveu diversos textos sobre o cineasta ao longo da década. o espaço, o som, a imagem, o ritmo, a representação dos actores, o enquadramento, a luz, etc. Todos contribuem para a criação da atmosfera, alguns mais do que outros, segundo a escolha do realizador" (GIL, 2011, p. 96). Gil desmonta em quatro braços-chaves a construção atmosférica: atmosfera temporal, espacial, visual e sonora. 
Júlia está de frente para o espelho e de costas para a câmera. O espelho alarga o campo de visão e permite que vejamos seu rosto e o de Marcos, também em quadro. O diálogo segue de forma que não percamos informações, deixando a cargo do espectador o foco. Há, no entanto, uma sedução na imagem do espelho e, para introduzir o flashback, Khouri aproxima a câmera e a fecha no reflexo. Nesse momento, estamos dentro de um leitmotiv khouriano, conforme descrito por Carmo. No filme, o espelho, se, de certo modo, provoca a reflexão de Júlia, também a aprisiona.

Frequentemente, Khouri filma Júlia em frente ao espelho. Os planos não expandem o campo, tampouco explicitam algum sentimento. Por vezes, vemos apenas seu reflexo. Seu corpo não está mais livre pelo cômodo e sim confinado a uma moldura. O quadro fílmico em si - bem como a película, a fotografia - é um espaço de prisão, que retém e restringe o ator/a cena materialmente. 0 espelho faz um novo recorte, um quadro dentro do quadro. Em determinado momento, o espelho funciona quase como um retrato, que evoca não só a história de Dorian Gray $^{10}$ - o retrato é sua liberdade ao mesmo tempo que sua prisão - como a quase onipresença de Rebecca, em Rebecca, a mulher inesquecível (1940), o melodrama psicológico com tons de horror gótico de Alfred Hitchcock.
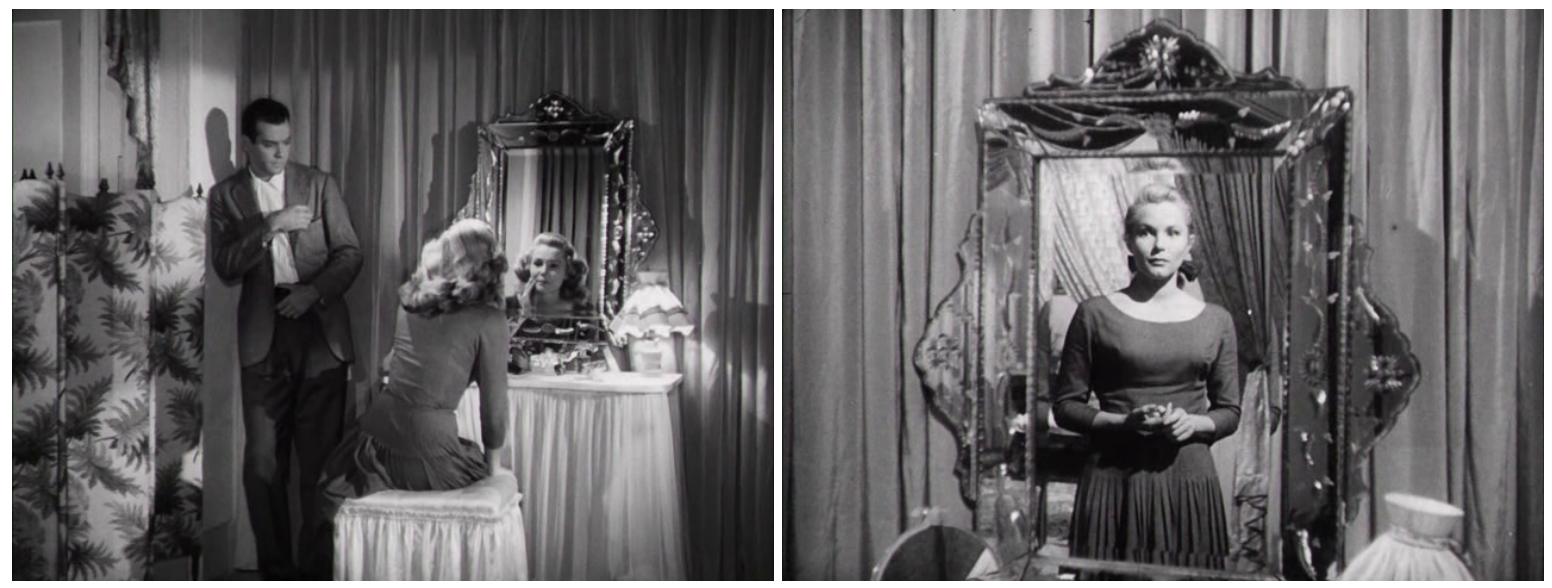

Figuras 10 e 11: O espelho como moldura e como retrato 
O que rege Estranho encontro, de certa forma, é o mistério - e a concepção visual do filme amplia esse estado de clausura em que a personagem parece se encontrar, pois reforça o caráter enigmático da narrativa. Pouco sabemos sobre os personagens ou sobre o que está acontecendo - por que Júlia está em pânico? Qual é a relação entre Marcos e o caseiro? Por que Júlia precisa se esconder? Por que não vemos o rosto de Hugo? etc. As informações são disponibilizadas aos poucos, o que por si cria uma apreensão do espectador. No entanto, não se trabalha mais a tensão pela ferramenta a ela associada, o suspense. Pelo contrário, busca-se o efeito quase oposto. Alfred Hitchcock (TRUFFAUT; SCOTT, 2004, p. 75) dizia que, para existir suspense, "é indispensável que o público esteja perfeitamente informado dos elementos presentes". O suspense opera com a oscilação da tensão, numa crescente, de forma a engajar o espectador na narrativa. Hitchcock levava essa operação ao limite, prolongando a experiência do público. No entanto, o suspense, assim como o susto no filme de horror, tem o contraponto imediato, que é a suspensão da tensão ao término do acontecimento. Ao falar de uma personagem de Easy virtue (1928), Hitchcock a definiu como um "poço de suspense", porém, uma vez que soube o que queria, "sentiu um grande alívio [...] e seu próprio suspense terminou".

Khouri, por outro lado, tensiona o mistério - que, para o cineasta britânico, "é raramente um suspense" (TRUFFAUT; SCOTT, 2004, p. 76). As pequenas surpresas ${ }^{11}$ são fundamentais para isso, uma vez que reforçam a instabilidade da trama. Durante o flashback, Hugo conta para Júlia algumas vezes sobre o acidente que o fez perder uma das pernas - uma granada que explodiu e deixou nela 25 estilhaços, provocando sua gangrena. Nós, assim como Júlia, sabemos, portanto, que Hugo

Aqui vale novamente retomar Hitchcock, que explica a diferença entre surpresa e suspense: "A diferença entre suspense e surpresa é muito simples, e costumo falar muito sobre isso. Mesmo assim, é frequente que haja confusão entre essas duas noções. Estamos conversando, talvez exista uma bomba debaixo desta mesa e nossa conversa é muito banal, não acontece nada de especial, e de repente: bum, explosão. O público fica surpreso, mas, antes que tenha se surpreendido, mostraram-Ihe uma cena absolutamente banal, destituída de interesse. Agora, examinemos o suspense. A bomba está debaixo da mesa e a plateia sabe disso, provavelmente porque viu o anarquista colocá-la. A plateia sabe que a bomba explodirá a uma hora e sabe que faltam quinze para a uma - há um relógio no cenário. De súbito, a mesma conversa banal fica interessantíssima porque o público participa da cena. Tem vontade de dizer aos personagens que estão na tela: 'Vocês não deveriam contar coisas tão banais, há uma bomba debaixo da mesa, e ela vai explodir"' (TRUFFAUT; SCOTT, 2004, p. 77). 
manca e usa uma bengala por causa desse problema. Nada, no entanto, prepara Júlia para o que ela vê quando adentra o quarto dele. A única informação que temos é o rosto da personagem, em um primeiro plano, que se contorce de medo e cuja intenção é reforçada por uma aproximação da câmera. O contracampo nos revela, num movimento lento de subida, começando do chão, a prótese de perna que Hugo usa. Khouri corta novamente para Júlia, em travelling, e depois para a perna, começando aberto na perna e fechando num detalhe. Pela forma como Khouri constrói a cena, intensifica-se a sensação de choque e pavor da personagem. Os travelling em direção ao rosto de Júlia são graduais, o que permite ao espectador ter tempo de examinar as emoções dela e criar uma identificação. O primeiro plano da prótese é lento e simula o ponto de vista da personagem, como se ela esquadrinhasse aquele objeto em sua frente. Assim que sabemos o que a apavora, voltamos ao seu rosto, que confirma sua reação.

O novo plano da perna é rápido, a música fica mais alta, como se Júlia fosse atingida por aquela imagem sinistra, como se entronizasse o mal. Avistarmos a prótese é um elemento de surpresa, em especial, porque não vimos o rosto de Hugo. A perna mecânica, ali, representa o próprio personagem e simboliza a monstruosidade que ele emana. Tal cena não só provoca uma oscilação de tensão, mas também engaja o interesse do espectador por conta da atmosfera para qual a cena contribui. A surpresa, no entanto, abre uma prerrogativa de instabilidade, pois, a qualquer momento, algo pode despertar o pavor da personagem.

Não só a prótese é usada como metonímia de Hugo. Tanto sua bengala quanto os relógios são associados à sua figura ao longo do filme. Por isso, Júlia diz odiá-los, por exemplo. Os relógios, em especial, marcam a narrativa e ganham um caráter antropomorfizado. Em uma das cenas do flashback, Júlia está só em uma sala com diversos relógios que Hugo colecionava. Temos, aqui, uma situação de medo semelhante à cena anteriormente descrita. Khouri alterna o rosto de Júlia com os diferentes relógios. A antropomorfização se dá pelo raccord do olhar a cada nova direção em que olha, um novo relógio. Os objetos são filmados em planos detalhes, o que reforça um efeito de intimidade para com eles. Segundo 
Balázs (2008, p. 91), "close-ups geralmente são revelações dramáticas sobre o que está realmente acontecendo sob a superfície das aparências". Quando aplicado a objetos, "ainda assim nos mostra o homem, pois o que torna os objetos expressivos são as expressões humanas projetadas nesses objetos" (BALÁZS, 2008, p. 91). Frente à despersonalização de Hugo, ao não mostrar seu rosto, os objetos - em especial os relógios - assumem essa identificação. Não é à toa que sempre que Júlia vê um relógio se apavora; da mesma forma que, quando com medo, ouve-se tic-tac e badaladas.
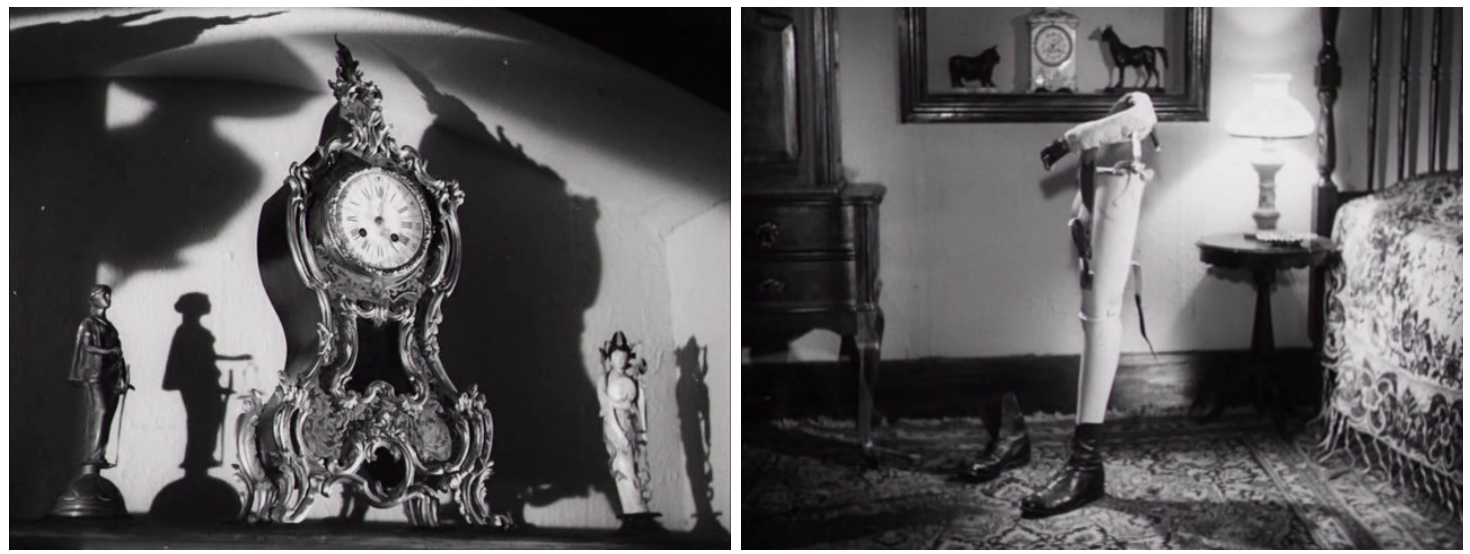

Figuras 12 e 13: Objetos antropomorfizados: o relógio e a prótese

As memórias a perturbam e ressoam nela o tempo todo. Ainda que não tenhamos acesso a elas visualmente, o som cumpre constantemente esse papel do lembrar. Por ter sido encontrada em pânico, por ser introspectiva e por ser mulher - numa sociedade essencialmente machista e patriarcal, dado que não escapa à sua construção no filme ${ }^{12}$ - , a sanidade de Júlia é logo questionada. Hugo colocara um anúncio no jornal pedindo que, quem tivesse informações sobre seu paradeiro, entrasse em contato, justificando que ela "sofre das faculdades mentais". A manchete não faz apenas Marcos questionar a história por ela contada, como também faz o espectador se indagar sobre a verdade do flashback, o que acentua a instabilidade com que compreendemos a história, em especial após 
a negação da face de Hugo, aumentando a apreensão. Mesmo que diegeticamente a dúvida seja dirimida, para o público ela permanece.

Para Júlia, existir, mesmo tendo conseguido fugir, é um eterno desespero, um medo constante do que pode vir a acontecer e de novamente estar diante de Hugo. Esse limiar entre a prisão e a liberdade - presente na antropomorfização de alguns objetos, nas tomadas com espelho, na renitência do som como elemento de memória, na expressão constante de pavor de Júlia, bem como no uso da técnica do claro/escuro ${ }^{13}$ - corrobora a construção da atmosfera de medo e paranoia que permeia o filme.

Tal elaboração está em consonância com o melodrama psicológico e o noir, conforme Turim (1989, p. 144), em que os filmes "são fascinados com a psique como agente do mal, causando a destruição do eu e de outros". Ela culmina no último ato. Com Wanda em casa e Rui desconfiado, Marcos realoca Júlia em um galpão de madeira velho e abandonado perto do píer. O espaço é iluminado apenas pela luz que entra pelas frestas e é amontoado de objetos empoeirados com motivos náuticos. Lá passa a tarde e a noite sozinha, fechada, esperando Marcos com uma solução. O filme alterna cenas de Marcos na casa com de Júlia no galpão. Por vezes, tais cenas evocam elementos do gênero horror, como um gato preto, trovoadas, entre outras características tidas como soturnas. 


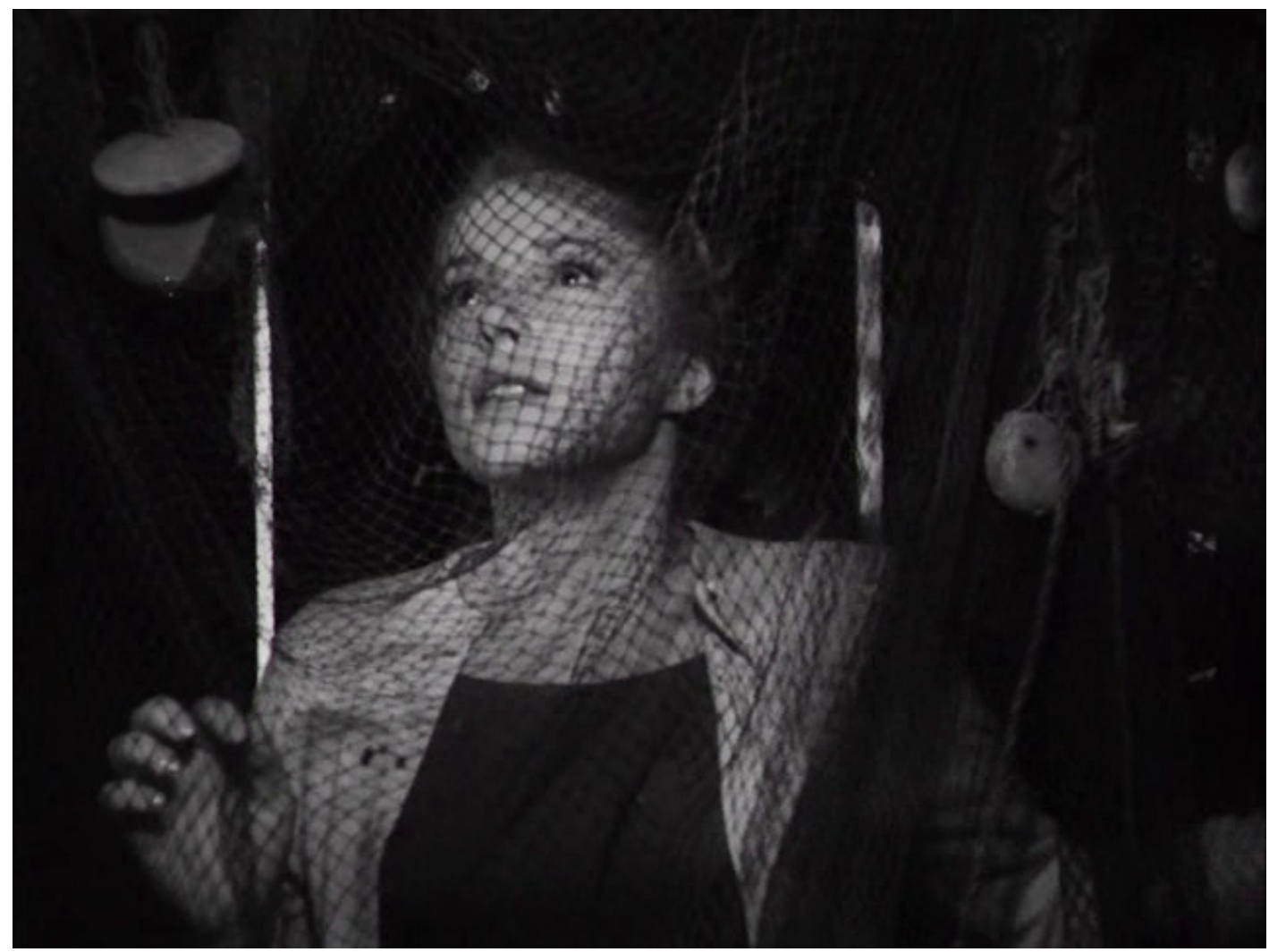

Figura 14: A rede como prisão

Ao amanhecer, vemos novamente Júlia. Um ruído compassado, similar ao tic-tac do relógio, faz-se ouvir. Ela, assustada, afasta-se da câmera e posicionase entre barras de ferro e uma rede de pesca - que já tinha aparecido antes, metaforizando a prisão em que ela se encontra. Júlia fica imóvel e a câmera corrige a posição. No espelho da porta do armário, no canto direito do quadro, aparece Hugo. É a primeira vez que o vemos frontalmente, como se, com o meganarrador do filme tendo reassumido seu papel após o flashback, tivéssemos voltado ao olhar onisciente e nos fosse permitido ver, enfim, o vilão. O som que perturba Júlia revela não ser só o do relógio, mas também o do passo de Hugo amparado pela bengala.

Nesse momento, uma série de procedimentos utilizados por Khouri para compor a atmosfera são reapropriados. O campo/contracampo e o close que vimos nos objetos inanimados são usados com a mesma função em Hugo, em especial, na cena dos relógios no flashback, fazendo uma conexão direta entre os objetos e o personagem. Alterna-se planos de Júlia apavorada com de Hugo 
impassível. A cada novo plano, o close é mais fechado no rosto dele, revertendo ao seu corpo a monstruosidade.

A aparição de Hugo no espelho do galpão aponta, novamente, a surpresa como elemento de construção atmosférica. Representa o auge da tensão, quando o medo da personagem de se reencontrar com o opressor se concretiza. A presença física dele em cena - e não como uma entidade sobrenatural a assombrar constantemente Júlia - reduz, num primeiro momento, o limiar entre a prisão e a liberdade que existe no filme. Numa trama clássica, espera-se que a protagonista atinja seus objetivos, o que não impede de se manter a tensão do espectador.

Nesse último ato, o espelho se reconfigura. Não simboliza mais a prisão e o espaço de especulação de Júlia. Serve como espaço de revelação para o espectador do que aprisionava a personagem, como se, após absorver as inquirições de Júlia, refletisse para nós a resposta. Hugo é reintroduzido em cena duas vezes pelo espelho. Primeiro, no galpão; depois, no vidro do carro que Júlia levanta, num instante em que parece que ele desistiu dela. Nos dois momentos, ele entra em cena - e no plano - através de seu reflexo. Ou seja, aparece inicialmente como assombração, como algo que não é da ordem material, para então provocar o mal concreto. Como afirma Carmo (2019, p. 119), "por sua própria natureza, o que o espelho reproduz a imagem de algo - não é real; e mesmo esta, por mais perfeita que pareça, nunca é igual àquilo que reflete, pois está sempre invertida". O espelho funciona, assim, a serviço da atmosfera como transição entre o mundo psicológico e o mundo físico.
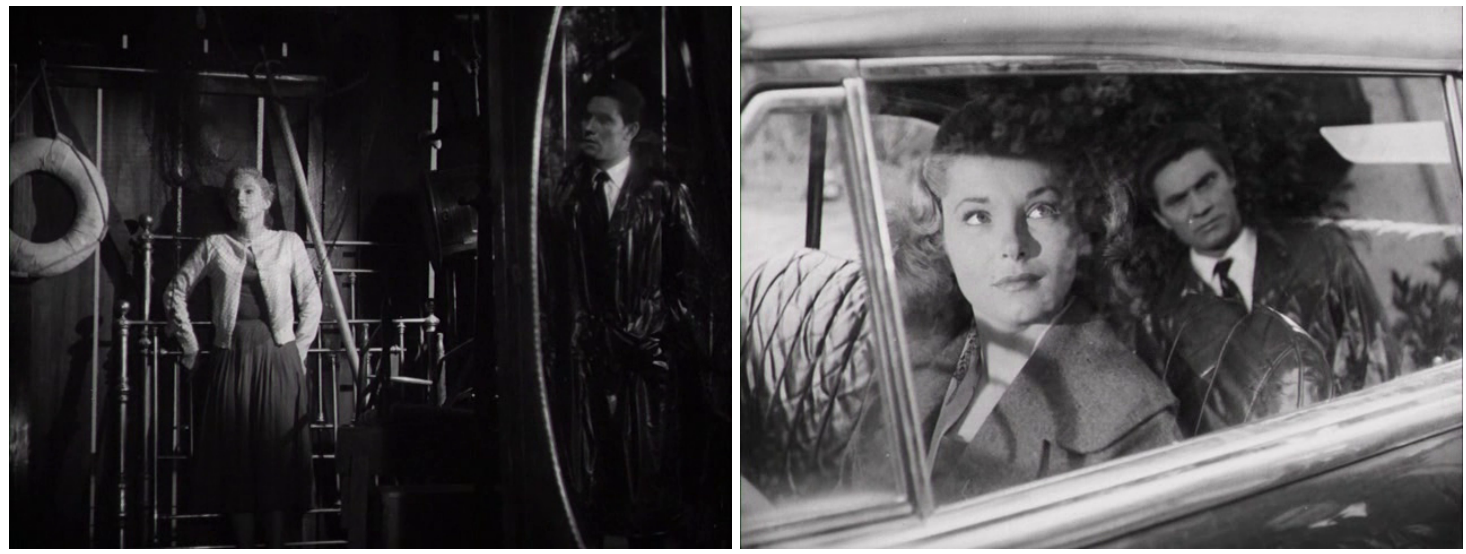

Figuras 15 e 16: O espelho e a surpresa: tensionamentos da construção atmosférica 


\section{Considerações finais}

À época do lançamento de Estranho encontro, Paulo Emilio Sales Gomes (1958) escreveu uma crítica, bastante reproduzida, que fazia paralelos entre Rio, zona norte (1957), de Nelson Pereira dos Santos, e o filme de Khouri. A produção carioca seria um "rascunho populista" enquanto a paulista, "um exercício brilhante". A ideia de Gomes é mostrar ambos os filmes como antípodas da nova produção brasileira. O artigo pode ser inserido nos debates intelectuais e artísticos da época, que opunha uma vertente nacionalista - a busca de um cinema realista autenticamente brasileiro - e uma universalista - narrativas de cunho universal realizadas com excelência técnica ${ }^{14}$. Gomes, que em 1960 escreveu Uma situação colonial?, foi um dos principais nomes da ala nacionalista. Ainda que na crítica Rascunhos e exercícios um filme não seja argumentado em detrimento do outro, já se percebe uma inclinação. Diz ele: "[...] se em Rio, zona norte [...] temos um autor que se revela inábil na manipulação do tipo de expressão estética que escolheu, Estranho encontro nos dá às vezes a impressão curiosa de um estilo à procura de um autor e de uma história" (GOMES, 1958, p. 5). Tal juízo parece, de certa forma, atrelado a uma afirmação anterior: "Khouri partiu do próprio cinema". Nisso, existe uma ideia de que o cineasta deve muito ao que viu; de que reproduz bem, mas Ihe falta a originalidade de autor.

No trecho destacado, Paulo Emilio Sales Gomes qualifica ambos os cineastas negativa ou positivamente - pela palavra "autor". O pensador travou bastante contato com a formulação da política francesa dos autores quando morou no país no início da década. O conceito não Ihe era estranho, portanto. Para Jean-Claude Bernardet (BERNARDET; REIS, 2018, p. 151), no entanto, o crítico "não adere à política, o que não impede que encontremos na sua produção numerosos elementos metodológicos que coincidem com a política". Existe, de qualquer forma, uma contaminação nos escritos de Gomes - e Bernardet reforça essas coincidências no final dos anos 1950 . 
Retomo o texto de Paulo Emilio, para além da discussão sobre o embate entre nacionalistas e universalistas, porque parece sintomática a posição de que há um estilo à procura de um autor, especialmente quando pensamos na carreira de Khouri como um todo. À primeira vista, Estranho encontro não parece um filme de Walter Hugo Khouri como o passamos a conhecer a partir de Noite vazia. A ideia de que "Khouri é antes de tudo um cineasta nascido em São Paulo, debatendo-se com as contradições e o isolamento da metrópole no cenário cultural brasileiro" (RAMOS, 2001, p. 6), por exemplo, só é possível efetivamente a partir de 1964. O mesmo se pode dizer do duplo papel da sexualidade nas relações humanas em seus filmes, em que, de um lado, "o sexo serve à diversão, ao encobrimento do tédio que sempre ameaça tomar conta dos espíritos; de outro, surge como esperança de apaziguamento da angústia existencial, sob condição de que seja encontrada uma mulher extraordinária" (PUCCI JR., 2001, p. 25). Uma série de textos tentam dar conta do estilo autoral de Khouri - Pucci Jr. (2001, 2011), Ramos (2001), Azeredo (1969), Carneiro (2019), Carmo (2019), por exemplo - e existe um consenso de que ele só se consolida com Noite vazia.

No entanto, ainda que não trabalhe tematicamente dentro do mesmo universo, há uma série de procedimentos, como visto, que podem ser associados ao cinema de Khouri. Há de fato um caráter de "exercício" em Estranho encontro, no sentido de que, dentro de sua vasta carreira, o filme ensaia para o que se tornaria a sua obra. O longa é sua segunda realização, feito ainda nos terrenos do cinema de estúdios - apesar de ser uma produção independente e não contar com a lógica do sistema de estúdios, ele é realizado fisicamente na Vera Cruz -, dentro de parâmetros clássicos. Não significa, no entanto, que não haja possibilidades de rupturas da adesão à ficção. A tensão entre o moderno e o clássico sempre foi trabalhada nas obras de Khouri. O uso da profundidade de campo ao invés do campo/contracampo nos diálogos, por exemplo, aponta já para uma dilatação do tempo, característica corriqueira em seu cinema. A construção atmosférica é fundamental para entender Estranho encontro. Se, aqui, ela está a serviço do medo, da paranoia e do mistério, em sua obra posterior estaria em prol da angústia, do tédio e da desilusão. 
No entanto, importa menos aqui se Estranho encontro pertence a uma "fase de juventude" que depois seria superada. Interessa que o filme, mesmo funcionando autonomamente, feito em um período de formação do cineasta, já assinalava características centrais de uma obra que se desenrolaria por 50 anos. Existem nele muitas marcas de enunciação ${ }^{15}$, diversas das quais podemos entender como marcas autorais. Não há Khouri sem uma narrativa ancorada na construção atmosférica mobilizada, entre outros, pela expressão facial. Não há Estranho encontro sem a paúra nos olhos de Andrea Bayard.

\section{Referências}

AZEREDO, E. Dossiê Khouri. Filme Cultura, Rio de Janeiro, n. 12, p. 14-28, maio/jun. 1969.

BALÁZS, B. Béla Balázs. In: XAVIER, I. (org.). A experiência do cinema. 4. ed. Rio de Janeiro: Graal, 2008. p. 75-99.

BAZIN, A. O que é o cinema?. São Paulo: Cosac Naify, 2014.

BERNARDET, J. C.; REIS, F. V. O autor no cinema: a política dos autores: França, Brasil: anos 1950 e 1960. 2. ed. São Paulo: Edições Sesc, 2018.

BORDWELL, D. O cinema clássico hollywoodiano: normas e princípios narrativos. In: RAMOS, F. P. (org.). Teoria contemporânea do cinema. v. 2. São Paulo: Editora Senac, 2005.

BURCH, N. Práxis do cinema. São Paulo: Perspectiva, 2008.

15 "Eis, pois, aquilo que seria a enunciação cinematográfica: o momento no qual o espectador, escapando ao efeito-ficção, teria a convicção de estar na presença da linguagem cinematográfica como tal" (GAUDREAULT; JOST, 2009, p. 62). 
CARMO, I. P. S. X. Rosto, tela, espelho: reflexões sobre o cinema de Walter Hugo Khouri. Aniki: Revista Portuguesa da Imagem em Movimento, Lisboa, v. 6, n. 2, ago. 2019.

CARNEIRO, G. H. P. O anjo da noite (1974): Khouri e o horror. Imagofagia: Revista de la Asociación Argentina de Estudios de Cine y Audiovisual, Buenos Aires, n. 19, abr. 2019.

CARNEIRO, G.; SILVA, H. P.; ALPENDRE, S. A crítica de cinema em São Paulo. In: SILVA, P. H. (org.). Trajetória da crítica de cinema no Brasil. Belo Horizonte: Letramento, 2019. p. 342-379.

DAYAN, D. O código tutor do cinema clássico. In: RAMOS, F. P. (org.). Teoria contemporânea do cinema. v. 1. São Paulo: Editora Senac, 2005. p. 321-337.

GALVÃO, M. R. Burguesia e o cinema: o caso Vera Cruz. Rio de Janeiro: Civilização Brasileira, 1981.

GAUDREAULT, A.; JOST, F. A narrativa cinematográfica. Brasília, DF: Editora UnB, 2009.

GIL, I. A atmosfera fílmica como consciência. Caleidoscópio: Revista de Comunicação e Cultura, Lisboa, n. 2, p. 95-101, jul. 2011.

GOMES, P. E. S. Rascunhos e exercícios. O Estado de S. Paulo, São Paulo, p. 5, 21 jun. 1958. Suplemento Literário.

GUIMARÃES, P. M. O rosto do ator: da expressão fotogênica ao reflexo externo. Sala Preta, São Paulo, v. 16, n. 2, p. 220-232, dez. 2016. 
MÜNSTERBERG, H. A memória e a imaginação. In: XAVIER, I. (org.). A experiência do cinema. 4. ed. Rio de Janeiro: Graal, 2008. p. 36-45.

PUCCI JR., R. L. Khouri. Revista Zingu!, São Paulo, n. 49, out. 2011. Disponível em: https://bit.ly/3fap5X3. Acesso em: 5 nov. 2019.

PUCCI JR., R. L. O equilíbrio das estrelas: filosofia e imagens no cinema de Walter Hugo Khouri. São Paulo: Annablume, 2001.

RAMOS, F. P. A coisa da imagem e a preponderância do afeto. In: CENTRO CULTURAL BANCO DO BRASIL. Retrospectiva Walter Hugo Khouri: meio século de cinema. São Paulo: Heco Produções, 2001. p. 6-9.

RAMOS, J. M. O. Cinema, estado e lutas culturais: anos 50/60/70. Rio de Janeiro: Paz e Terra, 1983.

TRUFFAUT, F.; SCOTT, H. Hitchcock/Truffaut: entrevistas. São Paulo: Companhia das Letras, 2004.

TURIM, M. Flashbacks in film: memory \& history. Nova Iorque: Routledge, 1989.

XAVIER, I. O discurso cinematográfico: a opacidade e a transparência. 4. ed. São Paulo: Paz e Terra, 2008b.

submetido em: 15 maio 2020 | aprovado em: 23 jul. 2020 